\title{
Application of stem cells perineural migration in patients with stroke
}

\begin{abstract}
Introduction: Cell technologies represent a perspective direction due to activation of endogenous reparative processes. Correction of impaired brain functions using stem cells is one of the most effective methods in complex therapy of neurodestructive processes.
\end{abstract}

Methods: Endoscopic perineural application of autologous mesenchymal stem cells (MSCs) as supplementary therapy in patients with stroke.

Results: 42 patients (27-73 y.o.) received 3-4 intranasal submucosal applications (injections of autologous MSCs in $10 \mathrm{ml}$ of suspension, $\sim 12 \times 10^{6}$ cells per injection) with 5-9days interval. According to NIHSS, all patients demonstrated progressive relief of neurological symptoms. This pilot project was performed as per guideline developed by the authors ("The method of stroke treatment using autologous mesenchymal stem cells from adipose tissue", No242-1218, the Ministry of Health of the Republic of Belarus, 2018).

Conclusion: There were no cases of repeated stroke observed within the first year of observation.

Keywords: stroke, mesenchymal stem cells, patient, perineural migration, somatotopic principle, treatment
Volume 9 Issue 2 - 2019

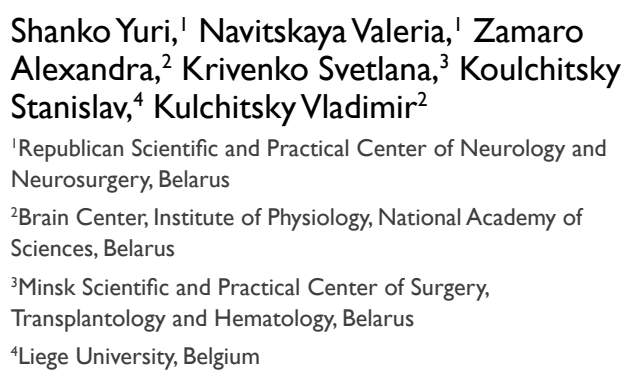

Correspondence: Vladimir Kulchitsky, Brain Center, Institute of Physiology, National Academy of Sciences, Belarus, Natl Acad Sci, 28 Akademicheskaya Street, Minsk, Belarus, Tel +375 17 2842458,Email vladi@fizio.bas-net.by

Received: April 20, 2019 | Published: April 30, 2019

\section{Letter to Editor}

Current therapy of stroke patients is not effective enough. ${ }^{1}$ Most of these patients experience performance decrement for a long period. ${ }^{1,2}$ This speaks for the need of new medical techniques development. Cell technologies represent a perspective direction due to activation of endogenous reparative processes ${ }^{3,4}$ Central migration and somatotopic distribution of MSCs in damaged brain areas after MSCs application to peripheral branches of cranial nerves was experimentally proved. ${ }^{5-7}$ For example, MSCs are revealed in damaged regions of anterior cranial fossa (namely, olfactory bulbs) after their submucosal application at superior nasal concha. ${ }^{8-10}$ And in contrast, application of MSCs to Meckel's cave (Gasser's node, trigeminal nerve) or perineural parts of vagus is followed by migration of cells to damaged nuclei in posterior cranial fossa. ${ }^{8,9}$

Somatotopic principle of perineural MSCs migration to damaged brain areas was used in adjuvant therapy of patients with stroke. ${ }^{11-14}$ The place of MSCs application depends on localization of damaged area: localization in anterior cranial fossa requires cells application to submucosa of superior nasal concha and localization in posterior cranial fossa - to inferior one. The advantage of this approach lies in its methodological simplicity and targeted delivery of cells to damaged areas - the main difference from the other methods of stem cell therapy (e.g. intracerebral or intrathecal applications)., ${ }^{3,4}$

In total 42 patients (27-73 y.o.) were subjected to this adjuvant therapy. Each patient received 3-4 intranasal submucosal applications (injections of autologous MSCs in $10 \mathrm{ml}$ of suspension, $\sim 12 \times 10^{6}$ cells per injection) with 5-9days interval. Autologous MSCs were separated from adipose tissue of patient's periumbilical area. Severity of stroke and recovery process were categorized using the NIH Stroke Scale Score. ${ }^{15}$ According to NIHSS, all patients demonstrated progressive relief of neurological symptoms. There were no cases of repeated stroke observed within the first year of observation.

Supplementary materials contain video records of patient $\mathrm{M}$. before and in 45 days after the course of therapeutic procedures, including intranasal application of autologous MSCs.

\section{Video statement}

Subject was consented for video recording and subsequent publication.

\section{Acknowledgments}

This article was funded by SSTP "New Methods of Medical Care", section "Transplantation of Cells, Tissues and Organs" (2016-2020).

\section{Conflicts of interest}

All listed authors concur with the submission of the manuscript; all authors have approved the final version. The authors have no financial or personal conflicts of interest.

\section{References}

1. Chen S, Singh RJ, Kamal N, et al. Improving care for acute in-hospital ischemic strokes-A narrative review. Int J Stroke. 2018;13(9):905-912.

2. Lioutas VA, Marchina S, Caplan LR, et al. Endotracheal Intubation and In-Hospital Mortality after Intracerebral Hemorrhage. Cerebrovasc Dis. 2018;45(5-6):270-278.

3. Rajkovic O, Potjewyd G, Pinteaux E. Regenerative Medicine Therapies for Targeting Neuroinflammation After Stroke. Front Neurol. 2018;9:734.

4. Kalladka D, Sinden J, Pollock K, et al. Human neural stem cells in patients with chronic ischaemic stroke (PISCES): a phase 1, first-in-man study. Lancet. 2016;388(10046):787-796.

5. Djupesland PG, Messina JC, Mahmoud RA. The nasal approach to delivering treatment for brain diseases: an anatomic, physiologic, and delivery technology overview. Ther Deliv. 2014;5(6):709-733.

6. Kulchitsky V, Zamaro A, Shanko Y, et al. Positive and negative aspects of cell technologies in cerebral diseases. J Neurol Stroke. 2018;8(2):87-88. 
7. Kulchitsky V, Zamaro A, Pashkevich S, et al. Nasolacrimal way of stem cells implantation. J Neurol Stroke 2018;8(2):110-111.

8. Kulchitsky V, Zamaro A, Shanko Y, et al. Prospects of Perineural Implantation of Stem Cells in Recovery of Neural Networks' Functions in Brain Diseases. Biomed J Sci\&Tech Res. 2018;10(3):1-4.

9. Shanko Y, Zamaro A, Takalchik-Stukach Y, et al. Mechanisms of Neural Network Structures Recovery in Brain Trauma. Biomed J Sci\&Tech Res. 2018;7(5):1-2.

10. Shanko Y, Krivenchuk D, Zamaro A, et al. Mutual Issues of Bioprinting and Stem Cell Technologies in Neural Tissue Repair. Biomed J Sci \& Tech Res. 2019;16(5):1-3.

11. Shanko Y, Navitskaya V, Zamaro A, et al. Prospects of Perineura Administration of Autologous Mesenchymal Stem Cells of Adipose Tissue in Patients with Cerebral Infarction. Biomed J Sci\&Tech Res. 2018;10(1):1-3.
12. Shanko Y, Navitskaya V, Zamaro A, et al. Somatotopic principle of perineural implantation of stem cells in patients with brain injuries. $J$ Neurol Stroke. 2018;8(5):259-261.

13. Kulchitsky V, Zamaro A, Krivenchuk D Koulchitsky S. Can Nerve Trunks Serve as Railroads for Stem Cells? Biomed J Sci \& Tech Res. 2019;15(1):1-4.

14. Zamaro A, Koulchitsky S, Ponomarenko G, et al. Perineural Migration of Autologous Stem Cells and Their Role in The Functional Reparation of Injured Internal Organs. Biomed J Sci \& Tech Res. 2019;16(1):1-4.

15. Jeyaseelan RD, Vargo MM, Chae J. National Institutes of Health Stroke Scale (NIHSS) as an Early Predictor of Poststroke Dysphagia. PM R. 2015;7(6):593-598. 